\title{
CULTURAL AWARENESS 2.0
}

\begin{abstract}
Ten years after the original research "Cultural Awareness of University Students of English: Background and Training” (Matić and Čorbić 2008) was published, we revisited the original questionnaire with similar aims as the original research: to explore cultural awareness of our students and to inform our decisions on how best to include elements of culture into our language classes to help our students in the development of intercultural competence. The students were the same age and in the same stage of their education (the first term of their first year) but while they answered some of the same questions as their peers ten years ago, the original questionnaire was modified and expanded to take into consideration the changed circumstances in which the freshmen of today acquire their knowledge of target language and culture. While at the start of the new millennium 'big-C' Culture was a staple of language and university courses and 'small-c' culture was learned hands-on in the target country only by the lucky few, the rapid globalization and spread of the Internet and digital media has changed the environment and the cultural and linguistic exposure that our first generation of 21 stcentury digital natives have been learning English in.
\end{abstract}

Key words: cultural awareness, developing intercultural competence, digital natives, university students

\section{Introduction}

Although a lot of research has been done in the field of culture and communication since the seminal works of Byram (1989) and Kramsch (1993), studies have proved that in very different contexts across the globe (Lee 2009, Rodriguez and Espinar 2015), there is still a lot more emphasis on what is usually termed "Big C" culture than on "small c" culture (underlying beliefs, and attitudes). Seen from that perspective, the 2007 research on cultural awareness of English language and literature freshmen at Belgrade University mostly concerned 'big C' culture, but it still seemed like a good idea to repeat it, since the intervening time has seen a rapid and perhaps unprecedented change in the environment and language exposure that marching globalization provided in terms of learning English, learning about the target culture(s), and more

\footnotetext{
${ }^{*}$ Faculty of Philology, University of Belgrade, Studentski trg 3, 11000 Belgrade, Serbia; e-mail: ivanazchorbic@gmail.com
} 
importantly, even in the attitude that our first entirely digital native generation bring to the classroom. Generation Zed-ers, as they are sometimes called, definitely seem to have new habits when it comes to learning and studying in general, and one of the issues to consider was certainly whether these new habits also influence their attitude and the knowledge and cultural awareness they finally acquire as a result. The students were in their freshman English course (now called G1 in the first term) and nearing the end of their first term when the expanded 2007 questionnaire was administered. The follow-up questionnaire was administered near the end of the second term (G2), to the same group of students. The original 2007 questionnaire was administered to the entire first year generation in the (then) Contemporary English I course (a total of 142 students, 32 male), who learned about target culture(s) as part of their Contemporary English I and Introduction to British Studies courses. The 2018 research included 60 students (20 male), and as mentioned above, comprised three parts: the original 2007 "cultural" questionnaire, the extension section on language and information habits, and the follow-up intercultural sensitivity questionnaire. Due to the length of the questionnaires we will not examine all responses to questions in detail but will focus on the most interesting differences and emerging trends in the comparison of 2007 and 2018 results. The questionnaires were anonymous and the participants could choose to respond to the questions or to leave them blank.

\section{The cultural information questionnaire}

The first part of the research contained mostly the same questions as in 2007; only 3 were changed with a total of 29. The questions covered different areas of "big C" knowledge (geography, education, food, politics, customs, etc.), and the final part was devoted to "attitude" questions.

\subsection{Geography}

Both the 2007 and the 2018 generations correctly identified "The Windy City" as not referring to New York, with 56 and 60 percent, respectively. Asked to identify the sights not in London, the students correctly chose Times Square in both generations (34.7\% in 2007, and $86.7 \%$ in 2018), but while the 2007 generation also selected Balmoral Castle in large numbers (57.3\%), only 6.67 percent of students marked it as outside of London in 2018. And while in both generations the students who chose to respond could correctly state where you can find The Tate Gallery, the Metropolitan, and Madame Tussauds (a number of the students even knew some of these existed in more than one location in 2018) in fairly similar percentages, and both generations had barely heard of Ayers Rock, the biggest difference between the generations was that in 
$2018,48.33 \%$ of students chose not to respond to this question at all. If we compare one of the more basic questions, such as What is the difference between the UK and Great Britain, we can observe that in $200734.7 \%$ answered correctly, 38.7\% gave an incorrect answer and $26.6 \%$ chose not to respond, while in 2018 the percentages were 28.3 for the correct answers and 13.3 for incorrect ones, which would have been fine if an overwhelming $58.4 \%$ hadn't chosen to skip the question!

\subsection{History}

In terms of identifying historical figures, in both generations students could correctly state who George Washington, Alfred the Great, Geoffrey Chaucer, and Winston Churchill were (in 2007: 70, 56, 61, and 56 percent respectively, and in 2018: $58.3,23.3,55$, and 41.7 percent respectively), while in 2007 hardly anyone knew who Sir Walter Raleigh was, and his replacement Noah Webster, or as one student put it, "the dictionary guy," fared only slightly better in 2018, and was correctly identified by 16.7 percent of students. This question was not perceived as tricky by the students, since in both generations the percentage of non-answers was low (5.3 in 2007 and 3.3 in 2018). When asked to explain the significance of some years in English history, in both generations 1066 seemed to be the most familiar year (38\% correctly identified it in 2007, and $43.3 \%$ in 2018), followed by 1215 (22\% in 2007 versus $15 \%$ 2018). The Spanish Armada (1588) did not ring many bells in either generation, and the biggest differences were in the final two items, 1776 being slightly more correctly identified in 2018 as the year of the Declaration of American Independence (13.3\% against only $6 \%$ in 2007), and the changed item for the 2018 generation - year 2016 being very correctly identified as the year of the Brexit referendum by 43.3 percent of students. However, the number of non-answers increased by $10 \%$ from 33 percent in 2007 to $43.3 \%$ in 2018.

\subsection{Festivals and customs}

One of the questions asked the students to identify British festivals among the following: Lord Mayor's Show, Halloween, Thanksgiving, Bonfire Night, and Mardi Gras. In the 2007 generation, Lord Mayor's Show (which appeared in one of the units in their Contemporary English textbook) was selected by $46.7 \%$ and Bonfire night by $38.7 \%$, while Thanksgiving and Halloween were mistakenly attributed to the British tradition by 17.3 and $5.3 \%$ of students respectively. In 2018, 46.67\% correctly identified Bonfire Night (we had a mini November 5th presentation in class), only 25\% made the right choice about Lord Mayor's Show, Thanksgiving and Halloween were only marked as British by 3.3 percent each, and Mardi Gras was believed to 
be British in $13.3 \%$ of cases (compared to $8 \%$ in 2007). This question was also not perceived as "dangerous", since a similar percentage of students (around 8\%) in both generations choose not to respond. When it came to customs and traditions, while in 2007 most students believed that you should arrive on time when invited to dinner in Britain (44 percent) or even early (40\%), probably perceiving the British as punctual, in 2018 only $33.3 \%$ thought you should be on time, $43 \%$ thought you should be early, and there was a significant increase of those believing that you should be 15 minutes late $(15 \%$ compared to $6.7 \%)$, probably modelling their ideas on Serbian customs. However, while in 2007 the majority of students could correctly identify that Boxing day is the day after Christmas (56\%), in 2018 only $30 \%$ were able to do so. Some $21.67 \%$ thought it was the day after New Year's Eve, and $36.67 \%$ thought it came after Easter. On the bright side, in 2018 there were $88.33 \%$ of students who knew that Black Friday was the first day after Thanksgiving (owing both to another class discussion and even more to the fact that Black Friday sales signs have come to appear in Belgrade shop windows in recent years). In addition, when asked to identify the context for the phrase "Break a leg!" $73.33 \%$ of 2018 students chose the theatre as their answer.

The most interesting question in this batch was number 6 in 2018 (What is the equivalent of the Serbian phrase "Prijatno" in English?), where the options were a) Have a good time! b) Enjoy! and c) nothing. Right around the time when the original questionnaire was administered in 2007, the phrase had begun to change meanings in Serbian, and was beginning to mean not just the same as the French Bon Appètit! (which would be roughly b) Enjoy! as said by an American waiter) but also something resembling a) Have a good time! which could be used on a number of occasions, including on TV or saying goodbye to friends or acquaintances when leaving. The expectation was that this change would spill over into students' choices when it came to this question. In 2007, most people picked b) Enjoy! - 70.7 percent, and to a lesser degree c) nothing, 25.3 percent. In 2018, contrary to expectations, $66.7 \%$ of students picked b) Enjoy! as their equivalent, with option a) only chosen in $5 \%$ of cases. It seems that the perception of the English equivalent has somehow been fixed on the American waiter usage, which shows students' awareness that the Serbian word has a wider range of communicative meanings.

\subsection{Stereotypes}

Comparing the results of the questionnaire when the students were supposed to select adjectives that applied to several English-speaking nationalities, which for the most part reflected their stereotypical ideas about each of them, especially considering 
that most had never met any Welshmen, Irishmen, or Australians face to face, we can briefly summarise the findings in one sentence: both in 2007 and in 2018, stereotypes were/are alive and kicking, although it might emerge at a closer look that the stereotypes do not necessarily resemble those held in the British Isles. We can see this in the order of adjectives most frequently attributed to each of the nationalities. Some of them are consistently seen in a favourable light, for example Australians, where the adjectives and their relative order seem to be the same from 2007 to 2018 (friendly, laid back, hardworking (2007), modest, outspoken). However, there have been some changes: Americans were seen as hardworking first in 2007, and then laid-back, outspoken, friendly, and hotheaded. The 2018 generation sees them as: outspoken, laid-back, friendly, stubborn, and hotheaded, with hardworking not making the shortest list at all. With the Scottish, seen in 2007 as stubborn, stingy, musical, hotheaded, and friendly, the order of adjectives was completely changed, with musical coming first, and stingy last, with only 3 people listing that option. Moreover, in 2007, the English were seen as reserved by $73.3 \%$ of people, followed by modest, hardworking, friendly, and polite. In 2018, only $41.67 \%$ of students labelled the English as reserved first, followed by stingy, modest, and hardworking, and polite did not even make the short list. The Irish seem to have kept the same image among the Serbs (2007 order of adjectives: musical, hotheaded, stubborn, and friendly, with stingy at the last place; 2018: musical, hotheaded, hardworking, stubborn, and friendly). The Welsh were perceived as modest, laid-back, hardworking, hotheaded, and stubborn in 2007, and in 2018 they were seen as: stubborn, stingy, hardworking, modest, with only 1 person adding 'musical' to the list. In our students' defence, there does not seem to be a lot of material on the Welsh in popular films or TV series, or not in the recent years, and the reputation for musicality that they enjoy in the UK has obviously not spread as far as Serbia.

\subsection{Literature}

Two of the questions asked students to name three British and then three American novelists. These are traditionally people like Shakespeare, Agatha Christie, Jane Austen, Dickens, the Bronte sisters, and other classics, who got a mention both in 2007 and in 2018, and there is usually a smattering of more contemporary names, such as Sophie Kinsella, Nicholas Sparks, and J.K. Rowling, who had quite a following in 2007 (20\% of responders) and slightly fewer fans in 2018 (10\%). These questions are also quite often skipped, $40 \%$ of people chose not to name any British novelists in 2018 , and $48 \%$ did not name any American ones, which is a slightly higher percentage than in 2007 (45\%). Hemingway, T. Williams, Mark Twain, and Walt Whitman made the list in 2018, along with Margaret Mitchell, Fitzgerald, and Stephen King, with 
George R. Martin making an appearance due to the Game of Thrones, and S. Collins due to Hunger Games. Another question that was consistently unpopular was: 'The Bard' is the nickname for which famous English writer? In 2007, 81.3\% of students opted out of answering that question, and only $9 \%$ correctly identified Shakespeare, with Byron as the runner-up. In 2018, 65\% of students chose not to respond, and $20 \%$ correctly wrote it was Shakespeare, with only one person voting for Dickens instead.

\subsection{Politics}

Another notoriously unpopular question is the one about which dynasty Queen Elizabeth belongs to. In $2007,56 \%$ of students did not respond to this question, while $36 \%$ got the answer right. In 2018, 40 out of 60 students chose not to answer, and only $15 \%$ knew the right answer. In informal conversations in class, and this was later confirmed by the information habits questionnaire, the 2018 generation admitted that they do not like following current events or the news in general, which might shed some light on their apparent disinterest in politics. In 2007, 34.7\% of students opted out of naming any political parties in the UK, 29.3\% mentioned conservatives, $24 \%$ mentioned the Labour party, and 18.7\% listed the Liberals. In 2018, 28 out of 60 people failed to respond to the question at all, $20 \%$ could correctly list UK parties, a more significant number knew that the main political parties in the US were the Republican and the Democratic party (36.66\%), and as a bonus, one person even mentioned UKIP in the UK.

\subsection{Confusing questions}

There were three questions where the emerging trend in comparing 2007 to 2018 answers seems to be confusion. In the examination of overall trends, both in 2007 and in 2018 students seem to choose the correct answer overall, although in 2018 we observe an apparently higher degree of confusion about some terms. For example, in the question where they had to correctly label the different names for schools as American or British (elementary, primary, high school, comprehensive, etc.) the majority of students got the answers right in both generations. However, in $201816.6 \%$ of students wrote that elementary school is a UK term, primary school was seen as a US expression by $21.6 \%$ of students, and the same percentage perceived secondary schools as belonging in America. At closer examination, the percentage of people who did not respond to the question is significantly higher in 2018 than in 2007 (only 1.3 in 2007 compared to $16.6 \%$ in 2019), which might partially account for the 2018 situation. However, in terms of percentages of correct answers to this question, the 2018 figures are consistently lower (in 2007: elementary $66.7 \%$, primary $64 \%$, 
secondary $56 \%$, comprehensive $70,7 \%$, grammar $77.3 \%$, high school $89.3 \%$; in 2018 : elementary $60 \%$, primary $55 \%$, secondary $55 \%$, comprehensive $65 \%$, grammar $68 \%$, and high school 78\%).

A similar trend was observed in the question where students had to match sports to the country (the UK or the US). Whereas in both generations cricket, Premier League, and Wimbledon were correctly identified as belonging to the UK, and baseball and Superbowl were correctly identified as American, with polo perceived as overwhelmingly British by both generations, there was a significant reversal when it comes to the terms football and rugby. In 2007, 70.7 percent of students correctly identified football as American and $26.7 \%$ identified rugby as British. However, in 2018, only $30 \%$ of students saw football as American, while $61.66 \%$ incorrectly assumed it was British. Rugby was perceived as American by $63.33 \%$ of students, with only $28.33 \%$ correctly picking the UK for this sport. This is both a vocabulary and cultural error, and seems to be most directly connected to the Serbian terms (where 'fudbal' means soccer, and 'ragbi' is both American football and rugby).

For a similarly constructed question, matching the food to either the US or the UK, two out of four items were easily sorted by both generations (pumpkin pie and Yorkshire pudding), while there seemed to be more confusion when it came to mince pie and cranberry sauce. In 2007, $50.7 \%$ of students made the correct choice for mince pie. In 2018, 56.66\% voted it to be a UK dish, while 31.66\% said it was American. This was the only question where there seemed to be a more even distribution of both answers among the female responders, and the same was observed for the cranberry sauce item, where girls seemed to be more indecisive than boys. In 2007, $61.3 \%$ of students saw cranberry sauce as American food, whereas in 2018 that percentage was $53.33 \%$. At the same time, $35 \%$ of the 2018 generation saw cranberry sauce as predominantly British.

\subsection{Attitude questions}

What we termed "attitude questions" in the introduction to this paper were in fact three questions designed to show the prevalent attitude of students towards learning about the culture and customs of target language countries, and the "degree of globalisation" or the degree to which they approved of adopting foreign customs or at least not disapproved of celebrating foreign holidays such as Halloween or Valentine's day. When asked to say whether they were in favour of celebrating these holidays or not, $16.67 \%$ of 2018 students chose not to respond, and a further $30 \%$ chose option c) no opinion. The narrow majority still said 'no' $-33,33$ percent, with the most common explanation being that these holidays are not part of our culture, or that we have our own holidays falling on the same date (Saints' Feast Days, St. Luka and St. Trifun to 
be exact). The $20 \%$ who said we should celebrate these holidays gave the explanations that "they transcend nations," "they are fun," or just "why not?".

In both 2007 and 2018 students were asked to rank sources of cultural information about target language countries in order of importance. The results can be found in Table 1. below:

\begin{tabular}{|c|l|c|l|}
\hline ranking & 2007 & & 2018 \\
\hline 1. & Films & 1. & The Internet \\
\hline 2. & Books & 2. & Music \\
\hline 3. & The Internet & 3. & Film \\
\hline 4. & British Studies & 4. & Books \\
\hline 5. & Contemporary English G1/2 & 5. & Contemporary English G1/2 \\
\hline 6. & Newspapers & 6. & Secondary school English \\
\hline 7. & Music & 7. & Newspapers \\
shared & $\begin{array}{l}\text { English classes } \\
\text { (secondary school) }\end{array}$ & 8. & British Studies \\
\hline 8. & Friends/family & 9. & Friends/family \\
\hline
\end{tabular}

Table 1. Sources of cultural information about L2 countries

We can see that the ranking has changed significantly, but a truly digital generation would see nothing unusual in turning to the Internet first. Friends and family, on the other hand, in most cases are Serbian just like our students, with no significant ties or experience with target language culture (more on that can be found in the Follow-up Questionnaire section) so they unsurprisingly ranked last with both generations.

The real attitude shift, however, was revealed by the last question to be dealt with in this section: Do you think that knowing about the culture of English-speaking countries is important for your future career as a language professional? In 2007, students mostly chose a) Yes, very important (56\%) and b) Yes, for general knowledge (40\%). Nobody at all chose c) Yes, but only for travel and socialising, and a meagre 1.3 percent chose d) No, not important. However, in 2018 the students' responses were markedly different: firstly, the majority response was actually b) only for general knowledge, with $46.67 \%$, 
the expected answer a) Yes, very important only getting 33, 33 percent. Item c) Yes, for travel and socialising was selected by 8.33 percent of this generation, and even d) No, not important garnered 3.33 percent. Only 8.33 percent of students chose not to respond. This means that within the span of a dozen years, learning about target language culture went from 'very important' for almost two thirds of the student population to being very important only to a third of them, with the rest of the generation attaching much less importance to this or at least seeing it in a more casual light.

\section{Language and Information Habits}

This part was administered only in 2018, at the same time as the "cultural information" questionnaire, as the extension on the final page. Some of the results shed light on the previously mentioned new trends, even if in some cases the insights were unexpected and rather disturbing. As many as $60 \%$ of students said they "rarely" followed news about current events in Serbia, with 6.67 percent admitting that they never did so. Of those who do, $70 \%$ follow them online, with $26.7 \%$ of them also watching news on TV. When it comes to following the news about target language countries, 55 percent of our students do so rarely, a further 28.3 do so on a weekly basis, and $75 \%$ of students do so online. Perhaps the most unexpected (and the most unwelcome) results were those pertaining to our students' reading habits (both in English and in Serbian). The situation with reading in Serbian is as follows: $41.6 \%$ read books once a month, 30 percent read fewer than three books per year, and only 5 people admitted to reading books daily. Reading in English seems to be a little more popular, with $33.3 \%$ reporting they read once a month, $16.67 \%$ read fewer than three books a year, but again only 4 people reported reading books in English on a daily basis. Add to this several informal conversations (in class and during oral exams) where students said that in their generation "it is not cool to read books" or that they "do not see the point of (reading) books," and it is safe to say that this instructor was appalled and alarmed, these opinions coming as they did from people who chose to study English language and literature at university. However, another surprising insight was that when they do read, this generation still prefers reading paper books to e-books.

When it comes to their online habits, the students found time spent online difficult to judge (and no wonder given that most of them have smartphones and computers and have Internet access twenty-four hours a day), the answers ranging from 5 hours a week to 19 hours a day, with $20 \%$ of students saying they spend "too much time" online without specifying what they mean by that. When they are online, they browse social networks, read online articles, and watch TV shows/films in English, (for this item they sometimes specified watching in Serbian as well), but they mostly chat and Skype in Serbian. Most of their online time in general is spent in watching films, chatting, browsing social 
networks, and reading online articles. In terms of acquiring information about the target culture(s) and everyday life in target countries, the most useful activities are perceived to be: watching films, reading online articles, and browsing social networks.

\section{The follow-up questionnaire}

This part of the research was administered with the participation of the same students at the end of the second term of the same academic year. There were 76 students (30 male and 46 female) who participated in this part of the research, with the average age of 19.2 years. All but five of them were born in Serbia. Only 2 people have not been abroad at all, but the majority have only been on school trips and/ or family trips of less than 15-day duration, with only 6 people spending more than two weeks abroad in any country, and only 5 people having visited any of the target language countries. Unfortunately, the situation in this regard has not significantly improved since 2007, and this was one of the facts that informed the choice of the instrument for measuring our students' intercultural sensitivity. Bennett, Bennett, and Allen (2003) make the connection of intercultural sensitivity (as a primarily affective factor) and foreign language proficiency, saying that there is a "typical fit between language proficiency levels and developmental levels of inter-cultural sensitivity" (Bennett, Bennett, and Allen 2003: 255). The instrument used was the original Chen and Starosta (2000) questionnaire, which breaks down intercultural sensitivity into six components (self-esteem, self-monitoring, open-mindedness, empathy, interaction involvement, and suspending judgment). Bearing in mind the fact that our students have not had a lot of sustained interaction with foreigners of any kind, judging by their reported foreign travel, and the fact that opportunities for meeting people from different cultures in Serbia are at best limited, this part of the research was intended to provide a rough idea of their perception of their intercultural sensitivity, given that the questionnaire is based on self-assessment. The questionnaire was administered in the original English, since our students' major is English.

Taking into account the arguments provided by Petrović et al. (2015) that some of the original Chen and Starosta questions do not work nearly as well in the Serbian context, only the average scores for the questions deemed valid by Petrovic et al. are given in the tables below. The Likert scale used was 1 through 5 , with 1 meaning 'strongly agree' and 5 meaning 'strongly disagree'. The answers were grouped according to Petrović et al. (Ibid), who divided the original Chen and Starosta questions that they deemed valid for our context into four groups: interaction enjoyment, interaction engagement, respect for differences, and interaction confidence. The tables below present our students' scores for the 19 questions Petrović et al. proposed to be used as a shortened version of the Chen and Starosta instrument for Serbian participants. 


\begin{tabular}{|l|l|}
\hline Interaction enjoyment & score \\
\hline I get upset easily when interacting with people from different cultures. & 4.34 \\
\hline I often get discouraged when I am with people from different cultures. & 4.22 \\
\hline I often feel useless when interacting with people from different cultures. & 4.13 \\
\hline I avoid those situations where I will have to deal with culturally-distinct persons. & 3.95 \\
\hline
\end{tabular}

Table 2. Average scores on the interaction enjoyment questions

\begin{tabular}{|l|l|}
\hline Interaction engagement & score \\
\hline I enjoy interacting with people from different cultures. & 1.51 \\
\hline $\begin{array}{l}\text { I often give positive responses to my culturally different counterpart during our } \\
\text { interaction. }\end{array}$ & 2.14 \\
\hline $\begin{array}{l}\text { I often show my culturally-distinct counterpart my understanding through verbal or } \\
\text { nonverbal cues. }\end{array}$ & 2.36 \\
\hline $\begin{array}{l}\text { I have a feeling of enjoyment towards differences between my culturally- distinct } \\
\text { counterpart and me. }\end{array}$ & 2.03. \\
\hline
\end{tabular}

Table 3. Average scores on the questions concerning interaction engagement

\begin{tabular}{|l|l|}
\hline Respect for differences & score \\
\hline I would not accept the opinions of people from different cultures. & 4.46 \\
\hline I think people from other cultures are narrow-minded. & 4 \\
\hline I respect the values of people from different cultures. & 1.7 \\
\hline I am open-minded to people from different cultures. & 1.54 \\
\hline
\end{tabular}

Table 4. Average scores on the questions indicating respect for differences

\begin{tabular}{|l|c|}
\hline Interaction confidence & score \\
\hline I am pretty sure of myself in interacting with people from different cultures. & 2.39 \\
\hline I always know what to say when interacting with people from different cultures. & 2.86 \\
\hline I feel confident when interacting with people from different cultures. & 2.53 \\
\hline
\end{tabular}

Table 5. Average scores on the questions indicating interaction confidence

Overall, our students believe themselves to be interculturally aware or sensitive to a satisfactory degree, even if they might not think in precisely these terms. Seen from the average scores above, they enjoy interactions with people from other cultures, and believe themselves adept enough at managing the interaction in a polite and successful 
manner. They see themselves as tolerant, free of prejudice, open-minded, and respectful towards interculturally different people. Their interaction confidence is on average the closest to mid-level, which is not surprising given how little experience the majority have had. While these scores on their own are encouraging, the biggest potential issue is that this faith in their interaction capabilities (and in the final instance even their open-minded attitude) is largely untested by actual interaction. Although it would be pointless and unrealistic to hope to train our students to adjust seamlessly and easily into an American or British environment (to mention the two most likely countries they might visit), the potential pitfalls in intercultural communication in this globalised world had better be addressed before our students graduate. This should involve both increasing their awareness of potential problems in communication in English (both when it serves as a lingua franca and when interacting with native speakers) and a more systematic approach to highlighting the differences in attitudes and underlying beliefs that our students might not yet be aware of, and which might prove to be stumbling blocks in communication even when their language is not the issue (Wage et al. 2005). Fortunately, we can assume that higher level linguistic courses that are in store for our students in their more senior years at university, such as those on pragmatics and discourse analysis, and the further courses on British (and American) Studies will help towards this goal but there is always room for improvement, especially in fostering a positive attitude towards other cultures and learning about them.

\section{Conclusion}

Generation Zed-ers, or the "Like" generation as they are sometimes called, are indeed different from their 2007 counterparts in several respects. Their level of factual "big C" knowledge, as evidenced by the first questionnaire, seems to be slightly lower than was the case with the class of 2007, they are more exposed to American English and culture (as evidenced by their familiarity with vocabulary, customs, political parties, etc.), and more prone to confusion and playing it safe (as evidenced by the increase in the percentage of non-answers). They are not interested in politics or history (this conclusion was supported by in-class discussions, where several students stated the opinion that they should know 'rough dates' of key events but do not see 'the point of learning things by heart'), which might explain their weaker grasp of facts of this kind. However, their primary sources of information are the Internet, films, and music, and they read far less than we as their teachers would want them to do, or than we did when we were in their shoes. This is all the more troubling since the importance of extensive reading, and reading for pleasure (Cho and Krashen 2019) for second language acquisition is well-known, and books in this scenario also become an overlooked but 
abundant source of cultural information. Our students believe themselves to be good at interacting with foreigners, tolerant, and open-minded, but they have not actually experienced enough or prolonged interaction that would provide them with a more realistic idea both of what this kind of interaction can be and what their real capabilities or even attitudes might be. At the same time, they seem to attach less importance to specialised university courses that should provide them with relevant information. Given that their online (and even offline) exposure to both English and information on English-speaking countries is highly customised and cannot be predicted, there is no guarantee that they will fill the knowledge gap on their own by the time they graduate. All of the above means that an overhaul of existing courses and a new approach for the new generation might be needed, in order not to just entice them to read more books but also to make them more aware that learning a language professionally is impossible without learning about its culture as well, and that their professional success might depend on their success as intercultural communicators just as much as on their command of grammar and vocabulary. In this endeavour, the technology that this generation so naturally embraces should not be seen as an enemy but as an ally. In all instances where there were directed (online) searches for information, minipresentations and/or videos, supported by class discussion, the cultural information was retained and the students subsequently performed well in the questionnaire. We as teachers might not be able to completely control their exposure to language and cultural information but we can and should direct their online activities and content consumption as part of course requirements, and a more systematic approach might be called for in this case. After all, Byram et al. (2018: 147) argue that "We have so far demonstrated that intercultural competence is not an automatic by-product of language teaching. Rather, language educators need to make a conscious decision to teach languages for intercultural communication."

\section{References}

Bennett, J., M. Bennett and W. Allen (2003). Developing Intercultural Competence in the Language Classroom. In D. L. Lange and R. M. Paige (eds.), Culture at the Core: Perspectives on culture in second language learning, Greenwich, $\mathrm{CN}$ : Information Age Publishing, 237-271.

Byram, M. (1989). Cultural Studies in Foreign Language Education. Clevedon, UK: Multilingual Matters.

Byram, M. and M. Wagner (2018). Making a difference: Language teaching for intercultural and international dialogue. Foreign Language Annals, 51, 140151. 
Chen, G.-M. and W. J. Starosta (2000). The Development and Validation of the Intercultural Sensitivity Scale. Human Communication, 3, 1-15.

Cho, K-S and S. Krashen (2019). Pleasure Reading in a Foreign Language and Competence in Speaking, Listening, Reading and Writing. (21 October 2019) $<$ http://journal.teflin.org/index.php/journal/article/view/728>.

Kramsch, C. (1993). Context and Culture in Language Teaching. Oxford: Oxford University Press.

Lee, K-Y. (2009). Treating culture: What 11 high school EFL conversation textbooks in South Korea do. English Teaching: Practice and Critique, 8 (1), 76-96.

Matić, J. and I. Čorbić (2008). Cultural Awareness of University Students of English: Background and Training. In K. Rasulić And I. Trbojević-Milošević (eds.), ELLSSAC Proceedings, Belgrade: Filološki fakultet, 763-781.

McDowall, D. (2004). An Illustrated History of Britain. Edinburgh Gate: Pearson Education Limited.

McDowall, D. (2002). Britain in Close-Up. Edinburgh Gate: Pearson Education Limited.

O'Connell, S. (2003). Focus on Advanced English C.A.E. Edinburgh Gate: Pearson Education Limited.

Petrović, D. et al. (2015). Intercultural Sensitivity Scale: Proposal for a Modified Serbian Version. Psihologija, 48(3), 199-212.

Rodriguez, A and A. Espinar (2015). General and Specific Culture Learning in EFL Textbooks Aimed at Adult Learners in Spain. Studia Anglica Posnaniensia, 50/1, 5-25. doi: 10.1515/stap-2015-0014 (21 October 2019) <https://www. researchgate.net/publication/283030637_General_and_Specific_Culture_ Learning_in_EFL_Textbooks_Aimed_at_Adult_Learners_in_Spain>.

Ware, P. and C. Kramsch (2005). Toward an Intercultural Stance: Teaching German and English through Telecollaboration. The Modern Language Journal, 89, 190-205. 